\title{
The Dawn Phenomenon: Comparison between Normal and Insulin-Dependent Diabetic Adolescents $^{1}$
}

\author{
S. ARSLANIAN ${ }^{2}$ Y. OHKI, D. J. BECKER, AND A. L. DRASH \\ Division of Pediatric Endocrinology, Metabolism, and Diabetes Mellitus, Children's Hospital, University of \\ Pittsburgh, Pittsburgh, Pennsylvania 15213 [S.A., D.J.B., A.L.D.] and Nippon Medical School, \\ First Hospital, Tokyo, Japan [Y.O.]
}

\begin{abstract}
To determine the role of insulin clearance in the dawn phenomenon, we studied 10 adolescents with IDDM in comparison to $\mathbf{1 0}$ healthy, matched control subjects reported previously. In diabetics, metabolic clearance rate of insulin was calculated during i.v. infusion of insulin from 0100 to $0430 \mathrm{~h}$ and from 0430 to $0800 \mathrm{~h}(0.17$ and $0.33 \mathrm{mU} / \mathrm{kg} / \mathrm{min}$, respectively), with a Harvard pump, while maintaining nocturnal euglycemia. In controls, metabolic clearance rate of insulin was calculated from the prehepatic insulin secretion rate based on C-peptide levels. In diabetic and control subjects, plasma glucose, free insulin, and glucagon concentrations were similar and did not change during the dawn period. However, metabolic clearance rate of insulin increased during the dawn period in diabetic $(9.42 \pm 0.91$ to $19.89 \pm 1.52 \mathrm{~mL} / \mathrm{kg} / \mathrm{min}, p<$ $0.0001)$ and control subjects $(4.87 \pm 1.11$ to $9.30 \pm 1.50$ $\mathrm{mL} / \mathrm{kg} / \mathrm{min}, p=0.008$ ). Plasma cortisol and adrenocorticotropic hormone levels increased and growth hormone (GH) decreased significantly during the dawn period. Diabetic adolescents had significantly higher plasma GH levels than control subjects throughout the night. We conclude the 1 ) increased insulin clearance is responsible for the dawn phenomenon in healthy and diabetic adolescents and 2) insulin resistance due to $\mathrm{GH}$ is an unlikely cause for the dawn phenomenon because diabetic subjects, despite higher GH levels, maintain plasma glucose levels similar to control subjects without requiring higher plasma free insulin concentrations. (Pediatr Res 31: 203-206, 1992)
\end{abstract}

\section{Abbreviations}

GH, growth hormone

IDDM, insulin-dependent diabetes mellitis

ACTH, adrenocorticotropic hormone

MCR, metabolic clearance rate

Since the first description of the dawn phenomenon a decade ago (1), its pathogenesis still remains controversial. There is continued debate as to whether increased insulin clearance (2-

Received August 8, 1991; accepted October 2, 1991.

Correspondence and reprint requests: Silva A. Arslanian, M.D., Division of Endocrinology, Children's Hospital of Pittsburgh, 3705 Fifth Avenue at DeSoto Street, Pittsburgh, PA 15213

Supported by USPHS Grant 5 M01-RR00086-25 (GCRC), 5 M01-RR0008425 (CAP), and the Renziehausen Fund.

'Presented at the 49th Annual Meeting of The American Diabetes Association, Detroit, June 1989.

${ }^{2}$ Recipient of FIRST Award (R29 HD27503-01) from National Institute of Child Health and Human Development (NICHD).
8) or decreased insulin action (9-13) is responsible for the increasing plasma glucose concentrations and/or insulin requirements between 0500 and $0900 \mathrm{~h}$ in diabetic as well as healthy subjects. Moreover, nocturnal GH secretion has been proposed as the causative factor leading to insulin resistance of the dawn period $(10,11,14,15)$. However, suppression of $\mathrm{GH}$ secretion does not invariably abolish the dawn phenomenon (16-18).

Puberty is characterized by increased GH secretion (19-20) and insulin resistance $(21)$, both of which are more pronounced in the diabetic adolescent (21-24). Given this background, one would expect a significant dawn phenomenon as a result of increased nocturnal GH secretion in healthy adolescents and, more so, in diabetic adolescents. However, in a previous investigation, we had demonstrated that the presence of the dawn phenomenon in healthy adolescents was characterized by an increase in metabolic clearance rate of insulin and not insulin resistance (25). Thus, the aim of this study was to evaluate the dawn phenomenon in adolescents with IDDM in comparison to the previously reported healthy subjects.

\section{MATERIALS AND METHODS}

Ten adolescents (five males, five females) with IDDM were studied. Their age was $16.6 \pm 1.3$ y (mean \pm SD) with Tanner developmental stages II-V. The duration of diabetes was $9.4 \pm$ $3.8 \mathrm{y}$, and glycosylated $\mathrm{Hb}$ was $9.8 \pm 2.3 \%$. Body mass index was $21.5 \pm 2.0 \mathrm{~kg} / \mathrm{m}^{2}$. All patients were receiving twice-daily intermediate-acting (Neutral Protamine Hagedorn) plus shortacting (regular) s.c. insulin injections with a mean daily insulin dose of $0.9 \pm 0.2 \mathrm{U} / \mathrm{kg}$. None of the patients had clinical or laboratory evidence of diabetic complications or other systemic diseases. Patients were compared with 10 nondiabetic healthy volunteers, reported previously (25), that were matched for age, pubertal development, and body mass index. Informed consent and assent was obtained from research participants and their parents. The study protocol was approved by the Human Rights Committee of Children's Hospital of Pittsburgh.

All studies were performed at the General Clinical Research Center of Children's Hospital of Pittsburgh. During evaluation, research participants consumed a weight-maintaining diet containing $55 \%$ carbohydrate, $30 \%$ fat, and $15 \%$ protein. Twentyfour $h$ before the study, all intermediate-acting insulins were discontinued in the IDDM subjects. Patients received regular insulin s.c. before meals, with the last meal at $2100 \mathrm{~h}$. Afterwards, they were placed at bed rest, and between 2130 and $2200 \mathrm{~h}$ a dorsal hand vein was cannulated for intermittent blood sampling and a contralateral arm vein for insulin infusion. A variable rate i.v. infusion of regular human insulin was begun with a Harvard pump at $2200 \mathrm{~h}$ aiming to normalize plasma glucose concentrations. By $0100 \mathrm{~h}$, all diabetic subjects were rendered euglycemic $(5.7 \pm 0.2 \mathrm{mmol} / \mathrm{L})$. From 0100 to $0430 \mathrm{~h}$, insulin was infused 
at $0.17 \mathrm{mU} / \mathrm{kg} / \mathrm{min}$, which was increased to $0.33 \mathrm{mU} / \mathrm{kg} / \mathrm{min}$ at 0430 to $0800 \mathrm{~h}$ to maintain normoglycemia and prevent the dawn-related increase in plasma glucose concentration. These infusion rates were determined from previous studies and our pilot studies to be sufficient to maintain overnight euglycemia $(4,10,26)$. A Harvard pump was used in all the studies to infuse insulin because it has been reported that insulin delivery may wane during prolonged Biostator infusion but not during Harvard pump infusion $(9,27)$.

Blood samples were taken at hourly intervals from 0100 through $0800 \mathrm{~h}$ for determination of plasma glucose (glucose oxidase method; YSI glucose analyzer, Yellow Springs Instrument Co., Yellow Springs, $\mathrm{OH}$ ) and free insulin (28), after immediate polyethylene glycol precipitation, glucagon, $\mathrm{GH}$, cortisol, and ACTH, as reported previously (25). The normal subjects had their insulin concentrations determined after polyethylene glycol precipitation exactly like the diabetic patients to have identical methodologies. Glycosylated $\mathrm{Hb}$ was measured by HPLC (Diamat; Bio-Rad, Hercules, CA), the normal range being 4.9 to $7.3 \%$. Insulin antibodies were determined as before (29) after removal of free insulin with acid charcoal. MCR of insulin in diabetic subjects was calculated as the ratio of mean insulin infusion rate to mean plasma free insulin concentration during the periods 0100 to 0400 and 0500 to $0800 \mathrm{~h}$ (30). The MCR of insulin in the nondiabetic group was calculated from prehepatic insulin secretion rate based on C-peptide levels as reported in our previous study (25).

Standard statistical methods were used, and data are expressed as mean \pm SEM. Differences between diabetic and nondiabetic subjects were analyzed using the $t$ test for unpaired samples. Within each group, the change in overnight hormone concentration was analyzed by repeated measures analysis of variance. Paired $t$ test was used to compare the periods 0100 to 0400 and 0500 to $0800 \mathrm{~h}$. Statistical significance was implied by $p \leq 0.05$.

\section{RESULTS}

Plasma glucose and free insulin concentrations (Figs. 1 and 2). In diabetic subjects, plasma glucose concentrations remained constant throughout the night with no difference between 0100 to 0400 and 0500 to $0800 \mathrm{~h}(5.2 \pm 0.3$ and $5.1 \pm 0.3 \mathrm{mmol} / \mathrm{L})$ (Figs. 1 and 2). There were no differences in nocturnal plasma glucose concentrations between diabetic and control subjects (Figs. 1 and 2). In the diabetic group, plasma glucose concentrations increased in four subjects and decreased in the remaining six subjects during the dawn period. There were no differences between these two groups except for $\mathrm{HbA}_{1}$ level, which was higher in the former $(11.5 \pm 1.0$ versus $8.7 \pm 0.8 \%, p=0.052)$. In the control group, plasma glucose concentrations increased in three and decreased in the other seven subjects.

Plasma free insulin levels in diabetic subjects at $0300 \mathrm{~h}$ and thereafter were significantly lower than that at $0100 \mathrm{~h}(122 \pm 12$ versus $175 \pm 14 \mathrm{pmol} / \mathrm{L}, p=0.05$ ), despite a constant rate infusion of insulin from 0100 to $0430 \mathrm{~h}$. There was no difference in free insulin concentrations between 0100 to 0400 and 0500 to $0800 \mathrm{~h}(141 \pm 13$ and $125 \pm 9 \mathrm{pmol} / \mathrm{L})$, despite higher insulin infusion rates after $0430 \mathrm{~h}$ (Figs. 1 and 2). There were no differences between diabetic and nondiabetic subjects (Figs. 1 and 2).

$M C R$ of insulin (Fig. 3). Insulin clearance increased during the period of 0500 to $0800 \mathrm{~h}$ compared with 0100 to $0400 \mathrm{~h}$ in diabetic $(19.89 \pm 1.52$ versus $9.42 \pm 0.91 \mathrm{~mL} / \mathrm{kg} / \mathrm{min} ; p<$ $0.001)$ and nondiabetic $(9.30 \pm 1.50$ versus $4.87 \pm 1.11 \mathrm{~mL} / \mathrm{kg} /$ min; $p=0.008$ ) subjects (25), with almost a doubling in both groups. Insulin clearance was twice as high in diabetic as in nondiabetic subjects. Insulin antibody levels were $22.4 \pm 5.9 \%$ in diabetic and $3.8 \pm 0.1 \%$ in nondiabetic subjects. Insulin clearance correlated with insulin antibody levels $(r=0.3)$ in diabetics, but this did not reach a significance level.

Plasma glucagon, GH, cortisol, and ACTH concentrations (Fig.
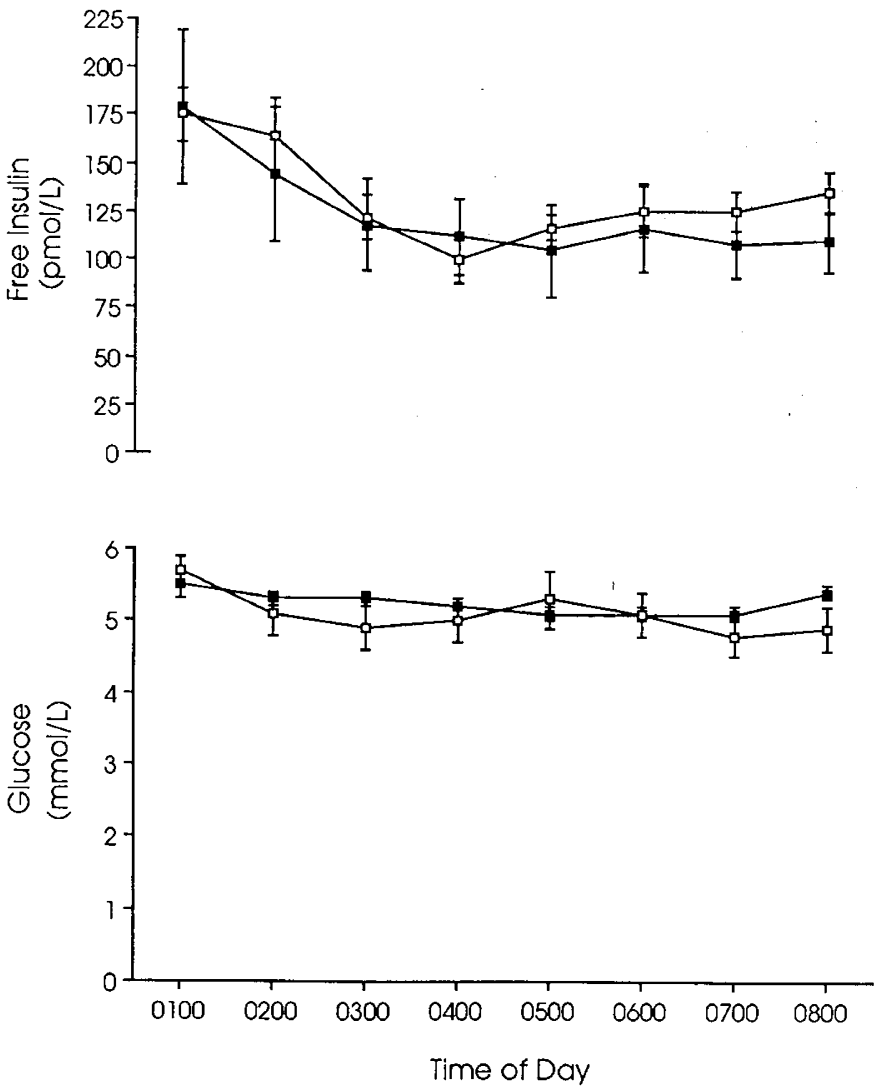

Fig. 1. Nocturnal profiles of plasma glucose and free insulin concentrations in IDDM (open squares) and control (closed squares) subjects.

4). In diabetic and nondiabetic subjects, plasma glucagon concentrations were similar and did not change overnight. In diabetic subjects, plasma GH concentrations decreased throughout the night from a peak of $26.1 \pm 4.5 \mu \mathrm{g} / \mathrm{L}$ at $0100 \mathrm{~h}$ to a nadir of 3.7 $\pm 1.0 \mu \mathrm{g} / \mathrm{L}$ at $0500 \mathrm{~h}(p<0.05)$. The mean plasma $\mathrm{GH}$ concentration between 0100 and 0400 was 2-fold that between 0500 and $0800 \mathrm{~h}(15.5 \pm 1.9$ versus $7.5 \pm 1.0 \mu \mathrm{g} / \mathrm{L} ; p=0.005)$. Plasma GH levels were twice as high in diabetic as in control subjects for both the 0100 to $0400 \mathrm{~h}$ period $(15.5 \pm 1.9$ versus $7.6 \pm 1.2 \mu \mathrm{g} / \mathrm{L} ; p=0.003)$ and the 0500 to $0800 \mathrm{~h}$ period $(7.5$ \pm 1.0 versus $3.0 \pm 0.9 \mu \mathrm{g} / \mathrm{L} ; p=0.004$ ). Plasma cortisol and $\mathrm{ACTH}$ concentrations increased through the night, with significantly higher levels between 0500 and $0800 \mathrm{~h}$ versus 0100 to $0400 \mathrm{~h}(384 \pm 44$ versus $124 \pm 19 \mathrm{nmol} / \mathrm{L}, p<0.001$ and $2.2 \pm$ 0.3 versus $1.5 \pm 0.2 \mathrm{pmol} / \mathrm{L}, p=0.017$, respectively). Cortisol and ACTH levels were similar in diabetic and nondiabetic subjects except for the period from 0500 to $0800 \mathrm{~h}$, where ACTH concentrations were lower in diabetics $(2.2 \pm 0.3$ versus $3.6 \pm$ $0.5 \mathrm{pmol} / \mathrm{L} ; p=0.05)$.

\section{DISCUSSION}

The present study demonstrates that the MCR of insulin increases during the dawn period in adolescents with IDDM. A doubling of insulin infusion rate at $0430 \mathrm{~h}$ prevents the dawnrelated increase in plasma glucose concentration without a change in plasma free insulin concentration. This doubling of exogenous insulin infusion rate is commensurate with our previous finding in healthy adolescents, in whom endogenous insulin secretion doubled to compensate for the increased insulin clearance (25). Furthermore, in the diabetic subjects, plasma free insulin concentrations continue to fall from 0100 to $0400 \mathrm{~h}$ despite a constant insulin replacement rate, indicating that insulin clearance was increasing during this period of the night relative to presleep values. 

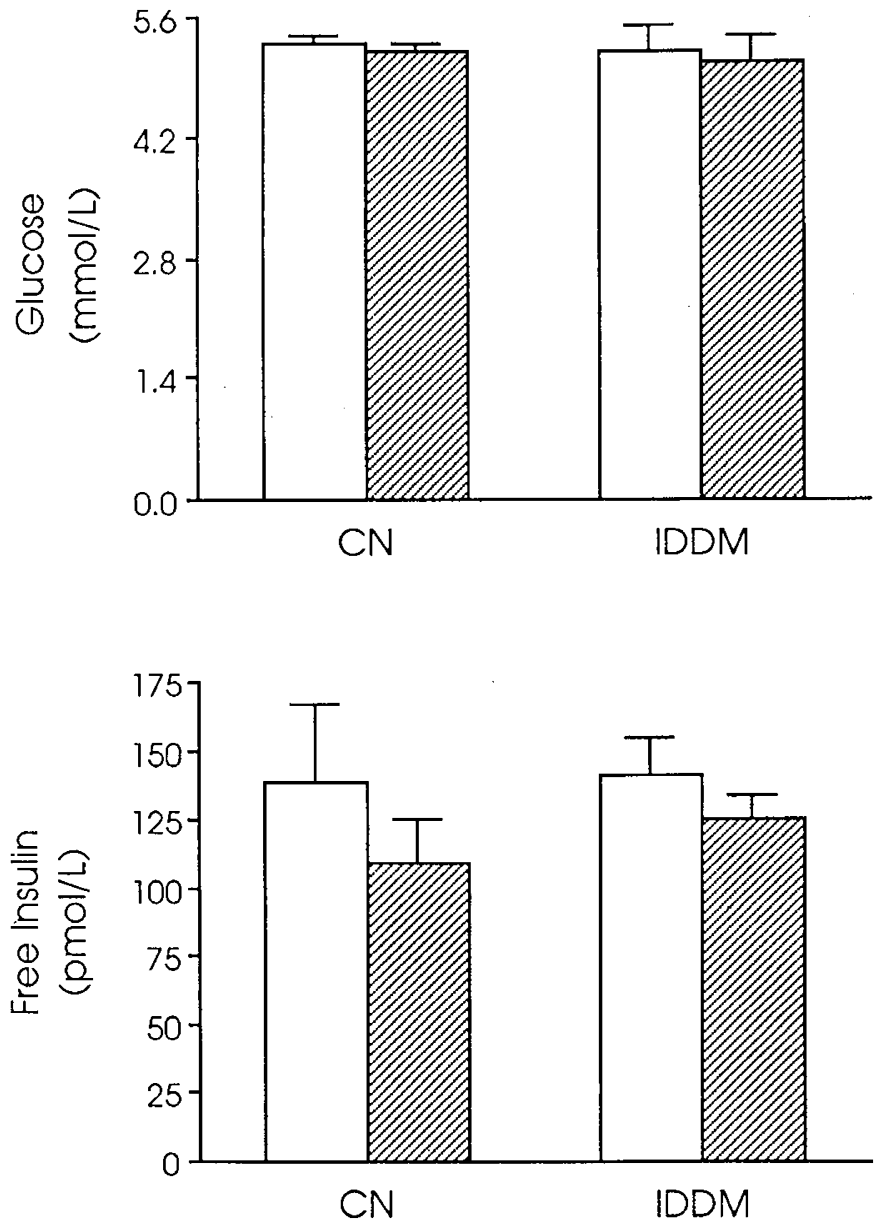

Fig. 2. Plasma glucose and free insulin concentrations between 0100 and $0400 \mathrm{~h}$ (open bars) ys 0500 to $0800 \mathrm{~h}$ (shaded bars) in control (CN) and IDDM subjects.

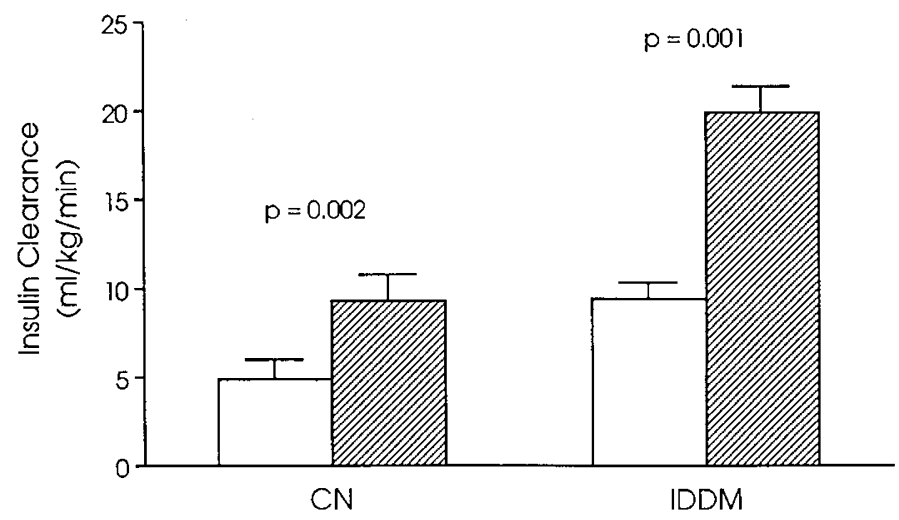

Fig. 3. Insulin clearance rate between 0100 and $0400 \mathrm{~h}$ (open bars) vs 0500 to $0800 \mathrm{~h}$ (shaded bars) in control $(C N)$ and IDDM subjects.

Several studies have suggested that MCR of insulin increases in the early morning in patients with IDDM (2-8). In the earlier studies $(4,5)$, a closed-loop insulin infusion device (Biostator GCIIS; Miles Laboratories, Elkhart, IN) was used. Later reports indicated that insulin delivery by the Biostator wanes over time and that the apparent overnight increase in insulin clearance observed in studies with the Biostator is artifactual as a result of pump-induced aggregation of insulin $(9,27)$. This was not observed when a Harvard pump was used (27). In the present studies, insulin was infused by a Harvard pump, and the recovery of insulin from the infusate at the site of entry to the patient ranged from 96 to $104 \%$ at the end of the experiment. Thus, it is highly unlikely that the increase in insulin clearance during
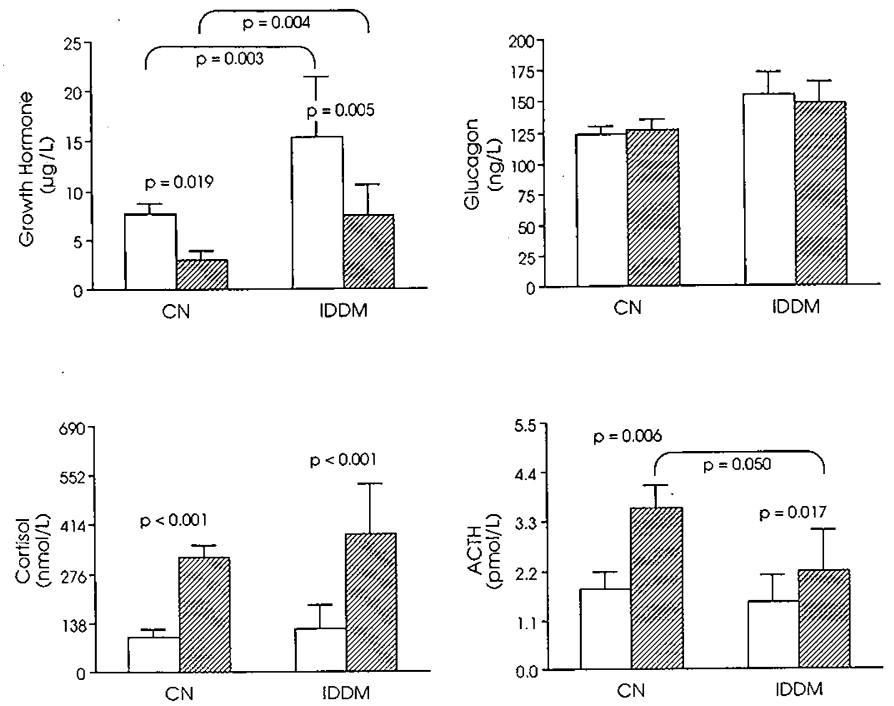

Fig. 4. Plasma $\mathrm{GH}$, glucagon, cortisol, and ACTH levels between 0100 and $0400 \mathrm{~h}$ (open bars) vs 0500 to $0800 \mathrm{~h}$ (shaded bars) in control $(C N)$ and IDDM subjects.

the dawn period is artifactual. Moreover, other investigators using Harvard pump infusion of insulin have demonstrated an overnight increase in MCR of insulin $(2,3,6,8)$ in diabetic patients. Furthermore, the observed increases in MCR of insulin in these studies are of comparable magnitude to each other (3, $4,8)$. The variation in the value of MCR of insulin in diabetic subjects among the various studies $(3,4,6,12)$ is in all likelihood the result of differences in the titer of circulating insulin antibodies. Diabetic patients with high insulin antibody titers have values for MCR that are considerably greater than those of nondiabetic subjects and diabetic patients with lower antibody levels $(31,32)$. This is evident in the present study population, where MCR of insulin is significantly higher at all times in diabetic subjects than in controls.

The mechanism(s) responsible for the increased insulin clearance during the dawn period remain obscure. However, a recent investigation suggests that $\mathrm{GH}$ contributes to the development of the dawn phenomenon by increasing insulin clearance (8). In this study, the authors demonstrated that insulin clearance increased during the dawn period in GH-sufficient IDDM subjects without a change in GH-deficient patients. Moreover, in a different study there is the suggestion that chronic suppression of $\mathrm{GH}$ with cholinergic blockade results in a reduction in insulin clearance (7). Additionally, it has been shown that GH administration in diabetic subjects resulted in a significant reduction in plasma free insulin concentrations (33). On the other hand, $\mathrm{GH}$ has been implicated to be responsible for the dawn phenomenon through induction of the hepatic and peripheral tissue insulin resistance $(10,11,13-15)$. If this were the case, then the diabetic subjects in the present study, who have GH concentrations twice as high as those of control subjects, would be expected to require high circulating plasma free insulin concentrations to maintain euglycemic conditions similar to controls. However, our data demonstrate that adolescents with IDDM maintain dawn blood glucose levels similar to control subjects with similar peripheral insulin concentrations. Moreover, if one takes into account that the portal to peripheral insulin concentration gradient is two to three in control subjects and one in IDDM patients $(34,35)$, then it becomes clear that portal insulin concentrations would be much lower in diabetic subjects. Despite this, plasma glucose concentrations are similar in diabetic and nondiabetic subjects during the dawn period, suggesting that the diabetic adolescents are more insulin sensitive (hepatic) (36) and, therefore, require lower portal insulin levels to achieve the same degree of euglycemia. Another explanation for, the lack of evi- 
dence for dawn-related insulin resistance in IDDM patients, despite 2-fold higher $\mathrm{GH}$ concentrations compared with control subjects, is that the elevated GH levels are metabolically inactive (37). It has been demonstrated that increases in plasma $\mathrm{GH}$ within the physiologic range $(\sim 9-16 \mathrm{ng} / \mathrm{mL})$ can cause insulin resistance in normal (38) and diabetic subjects (39). The lack of evidence for insulin resistance during the dawn period in our adolescents with IDDM despite the 2-fold higher GH levels would suggest that insulin resistance is an unlikely cause for the dawn phenomenon, especially when this is interpreted in the context of changes in the healthy controls.

In conclusion, the present study demonstrates that MCR of insulin increases during the dawn period in healthy and diabetic adolescents. This increased insulin metabolism influences the early-morning insulin requirements, but not the plasma glucose levels, as long as insulinization remains adequate by the compensatory increase in insulin secretion in normal subjects or by exogenous insulin infusion in diabetic subjects. The higher nocturnal $\mathrm{GH}$ concentration in diabetic adolescents is not associated with insulin resistance compared with healthy controls. Whether elevated $\mathrm{GH}$ levels play a role in the observed changes in insulin clearance during the dawn period between diabetic and normal subjects remains to be clarified.

\section{REFERENCES}

1. Schmidt MI, Hadji-Georgopoulos A, Rendell M, Margolis S, Kowarski A 1981 The dawn phenomenon, an early morning glucose rise; implications for diabetic intraday blood glucose variation. Diabetes Care 4:579-580

2. Skor DA, White NH, Thomas L, Santiago JV 1984 Relative roles of insulin clearance and insulin sensitivity in the prebreakfast increase in insulin requirements in insulin dependent diabetic patients. Diabetes 33:60-63

3. Dux S, White NH, Skor DA, Santiago JV 1985 Insulin clearance contributes to the variability of nocturnal insulin requirements in insulin dependent diabetes mellitus. Diabetes 34:1260-1265

4. Clarke WL, Haymond MW, Santiago JV 1980 Overnight basal insulin requirements in fasting insulin-dependent diabetics. Diabetes 29:78-80

5. Skor DA, White NH, Thomas L, Santiago JV 1985 Influence of growth hormone on overnight insulin requirements in insulin-dependent diabetes. Diabetes 34:135-139

6. Kerner W, Navascues I, Torres AA, Pfeifer EF 1984 Studies on the pathogenesis of the dawn phenomenon in insulin dependent diabetic patients. Metabolism 33:458-464

7. Atiea JA, Creagh F, Page M, Owens DR, Scanlon MF, Peters JR 1989 Early morning hyperglycemia in insulin-dependent diabetes: acute and sustained effects of cholinergic blockade. J Clin Endocrinol Metab 69:390-395

8. Boyle PJ, Avogaro A, Smith L, Shah SD, Bier DM, Cryer PE, Santiago JV 1989 Absence of the dawn phenomenon and abnormal lipolysis in growth hormone deficient IDDM's (GHD-IDDM's). Diabetes 38:3A(abstr)

9. Campbell PJ, Gerich JE 1986 Occurrence of dawn phenomenon without change in insulin clearance in patients with insulin dependent diabetes mellitus. Diabetes 35:749-752

10. Campbell PJ, Bolli GB, Cryer PE, Gerich JE 1985 Sequence of events during development of the dawn phenomenon in insulin-dependent diabetes mellitus. Metabolism 34:1100-1104

11. Campbell P, Bolli G, Cryer P, Gerich JE 1985 Pathogenesis of the dawn phenomenon in patients with insulin dependent diabetes mellitus. $\mathrm{N}$ Engl J Med 312:1473-1479

12. DeFeo P, Perriello G, Ventura MM, Calcinaro F, Basta G, Lolli C, Cruciani C, Dell'Olio A, Santeusanio F, Brunetti P, Bolli GB 1986 Studies on overnight insulin requirements and metabolic clearance rates of insulin in normal and diabetic man: relevance to the pathogenesis of the dawn phenomenon. Diabetologia 29:475-480

13. Koivisto VA, Yki-Jarvinen H, Helve E, Karonen SL, Pelkonen R 1986 Pathogenesis and prevention of the dawn phenomenon in diabetic patients treated with CSII. Diabetes 35:78-82

14. Campbell PJ, Bolli GB, Gerich JE 1988 Prevention of the dawn phenomenon (early morning hyperglycemia) in insulin dependent diabetes mellitus by bedtime intranasal administration of long acting somatostatin analog. Metabolism 37:34-37

15. Perriello G, DeFeo P, Torlone E, Fanelli C, Santeusanio F, Brunetti P, Bolli GB 1990 Nocturnal spikes of growth hormone secretion cause the dawn phenomenon in Type I (insulin-dependent) diabetes mellitus by decreasing hepatic (and extrahepatic) sensitivity to insulin in the absence of insulin waning. Diabetologia 33:52-59

16. Johnston DG, Davies RR, Alberti KGMM, Miller M, Turner SJ, Watson M 1986 Effects of SMS 202-995 on intermediary metabolism and endocrine status in normal and diabetic humans. Am J Med 81:88-91

17. Atiea JA, Creagh F, Page M, Owens DR, Scanlon MF, Peters JR 1989 Earlymorning hyperglycemia in IDDM. Diabetes Care 12:443-448

18. Aarsen RSR, Bruining GJ, Grose WFA, vanStrik R, Lamberts SWJ, Harris AG 1987 Long-acting somatostatin analogue (Sandostatin) reduces late night insulinopenic ketogenesis in diabetic teenagers. Acta Endocrinol [Suppl] 286:45

19. Mauras M, Blizzard RM, Link K, Johnson ML, Rogol AD, Veldhuis JD 1987 Augmentation of growth hormone secretion during puberty: evidence for a pulse amplitude-modulated phenomenon. J Clin Endocrinol Metab 64:596601

20. Martha Jr PM, Rogol AD, Veldhuis JD, Kerrigan JR, Goodman DW, Blizzard RM 1989 Alterations in the pulsatile properties of circulating growth hormone concentrations during puberty in boys. $J$ Clin Endocrinol Metab 69:563-570

21. Amiel SA, Sherwin RS, Simonson DC, Lauritano AA, Tamborlane WV 1986 Impaired insulin action in puberty. N Engl J Med 315:215-219

22. Arslanian S, Nixon PA, Becker D, Drash AL 1990 Impact of physical fitness and glycemic control on in vivo insulin action in adolescents with IDDM. Diabetes Care 13:9-15

23. Horner JM, Kemp SF, Hintz RL 1981 Growth hormone and somatomedin in insulin-dependent diabetes mellitus. J Clin Endocrinol Metab 53:1148-1153

24. Edge JA, Dunger DB, Matthews DR, Gilbert JP, Smith CP 1990 Increased overnight growth hormone concentrations in diabetic compared with normal adolescents. J Clin Endocrinol Metab 71:1356-1362

25. Arslanian S, Ohki Y, Becker DJ, Drash AL 1990 Demonstration of a dawn phenomenon in normal adolescents. Horm Res 34:27-32

26. Bolli GB, Gerich JE 1984 The "dawn phenomenon." A common occurrence in both non-insulin dependent and insulin-dependent diabetes mellitus. $\mathrm{N}$ Engl J Med 310:746-750

27. Brennan JR, Gebhart SSP, Blackard WB 1985 Pump-induced insulin aggregation: a problem with the biostator. Diabetes 34:353-359

28. Nakagawa S, Nakayama H, Sasaki T, Yoshino K, Yu YY, Shinozaki K, Aoki S, Mashimo K 1973 A simple method for the determination of serum free insulin levels in insulin-treated patients. Diabetes 22:590-600

29. Arslanian SA, Becker DJ, Rabin B, Atchison R, Eberhardt M, Cavender D Dorman J, Drash AL 1985 Correlates of insulin antibodies in newly diagnosed children with insulin-dependent diabetes before insulin therapy. Diabetes 34:926-930

30. DeFronzo R, Tobin JD, Andres R 1979 Glucose clamp technique: method for quantifying insulin secretion and resistance. Am J Physiol 237:E214-E223

31. VanHaeften TW, Bolli GB, Dimitriadis GD, Gottesman IS, Horwitz DL, Gerich JE 1986 Effect of insulin antibodies and their kinetic characteristics on plasma free insulin dynamics in patients with diabetes mellitus. Metabolism 35:649-656

32. Waldhausl W, Bratusch-Marrain P, Kruse V, Jensen I, Nowotny P, Vierhapper H 1985 Effect of insulin antibodies on insulin pharmacokinetics and glucose utilization in insulin-dependent diabetic patients. Diabetes 34:166-173

33. Schade DS, Eaton RP, Peake GT 1978 The regulation of plasma ketone body concentration by counter-regulatory hormones in man. Diabetes 27:916924

34. Blackard WG, Nelson NC 1970 Portal and peripheral vein immunoreactive insulin concentrations before and after glucose infusion. Diabetes 19:302306

35. Horwitz D, Starr J, Mako M, Blackard W, Rubenstein A 1975 Proinsulin, insulin and C-peptide concentrations in human portal and peripheral blood. J Clin Invest 55:1278-1283

36. Hother-Nielsen O, Schmitz O, Bak J, Beck-Nielsen H 1987 Enhanced hepatic insulin sensitivity, but peripheral insulin resistance in patients with type I (insulin-dependent) diabetes. Diabetologia 30:834-840

37. Gerich JE 1984 Role of growth hormone in diabetes mellitus N Engl J Med 310:848-849

38. Rizza RA, Mandarino LJ, Gerich JE 1982 Effects of growth hormone on insulin action in man. Diabetes 31:663-669

39. Press M, Tamborlane WV, Sherwin RS 1984 Importance of raised growth hormone levels in mediating the metabolic derangements of diabetes. $\mathrm{N} \mathrm{Engl}$ J Med 310:810-815 